\title{
Determination of thermo-mechanical properties of recycled polyurethane from glycolysis polyol
}

\author{
James K. Njuguna ${ }^{a}$, Peter Muchiria ${ }^{a}$, Fredrick M. Mwema ${ }^{a}$, Nancy W. Karuri ${ }^{b, *}$, \\ Michael Herzog ${ }^{c}$, Kiril Dimitrov ${ }^{c}$ \\ a Department of Mechanical Engineering - Dedan Kimathi University of Technology, 657-10100, Kenya \\ ${ }^{\mathrm{b}}$ Department of Chemical Engineering - Dedan Kimathi University of Technology, 657-10100, Kenya \\ ${ }^{\mathrm{c}}$ Faculty of Engineering and Natural Sciences - Technical University of Applied Science Wildau, Hochschulring 1, D-15745 Wildau, \\ Germany
}

\section{A R T I C L E I N F O}

\section{Article history:}

Received 7 January 2021

Revised 20 February 2021

Accepted 19 March 2021

\section{Keywords:}

polyurethane foam

recycling

glycolysis

rigid polyurethane

thermo-mechanical properties

circular economy

\begin{abstract}
A B S T R A C T
Polyurethane foam is one of the most versatile polymers widely used in the automotive industry. However, due to the rising amount of polyurethane foam waste in the environment, there is growing research attention focusing on circular economy solutions to closing the material loop. This study aimed to determine the possible changes in thermomechanical properties between rigid polyurethane prepared using polyols derived from depolymerization of commercial polyurethane foam with benchmark rigid polyurethane (Ben $\mathrm{PU}$ ). Polyurethane foams containing dispersion polyol were reacted with dipropylene glycol (DPG) and diethylene glycol (DEG) with a ratio of DPG: DEG of 1:1 in the presence of a consumable catalyst (Di-n-butyl amine). The recovered polyol was used as a raw material replacing $100 \%$ benchmark rigid polyurethane petroleum-based polyester polyol to produce the recycled polyurethane (Rec PU). Thermal analysis was conducted to measure the recycled polyurethane's glass transition temperatures $\left(T_{g}\right)$ using differential scanning calorimetry (DSC). Tensile strength, elastic modulus, toughness, and hardness test of the recycled polyurethane were conducted under three different temperatures; $24{ }^{\circ} \mathrm{C}, 40^{\circ} \mathrm{C}$, and $60^{\circ} \mathrm{C}$. From the DSC results, the glass transition temperatures for the recycled and the benchmark rigid polyurethane occurred at $43^{\circ} \mathrm{C}$ and $50.4^{\circ} \mathrm{C}$, respectively. Both polymers showed the brittle-ductile transition from $24^{\circ} \mathrm{C}$ to $40^{\circ} \mathrm{C}$. Tensile strength for recycled polyurethane was lower than that of benchmark rigid polyurethane by $29-43 \%$ and a corresponding $24-$ $50 \%$ decrease in elastic modulus. Recycled polyurethane recorded lower toughness than petroleum-based pure polyurethane by $13-16 \%$. However, the recycled polymer recorded high shored D values than the benchmark rigid polyurethane by $9-29 \%$. This study reveals that recycled polyol could be used as feedstock for polyurethane production with applications tailored to its mechanical properties.
\end{abstract}

(C) 2021 Published by Elsevier B.V. on behalf of African Institute of Mathematical Sciences / Next Einstein Initiative. This is an open access article under the CC BY-NC-ND license (http://creativecommons.org/licenses/by-nc-nd/4.0/)

\footnotetext{
* Corresponding author.

E-mail address: nancy.karuri@dkut.ac.ke (N.W. Karuri).
} 


\section{Introduction}

Polymer recycling processes attract significant attention as a direct result of the enforcement of environmental legislation. Massive enforcement of the environmental laws has provoked an extensive re-examination of various approaches to utilize end-of-life plastic waste as an alternative to landfill disposal. Creative and profitable recycling methods for polymers have been proposed to reduce their environmental impact by removing them from the waste stream and recovering the valuable material due to the increasing cost of raw material and regulations on its disposal [1]. Polyurethane is one of the most versatile and adaptable polymer materials widely used in different applications, which makes its recycling an urgent task. A broad spectrum of polyurethane specialties, linear or reticulated, can be produced to meet each specific application's need depending on the polyol and the isocyanate employed in the reaction and the extension of the reactions involved [2]. The reaction's mechanism is a nucleophilic addition of oxygen of an alcohol group to the carbon of the isocyanate group while its active hydrogen is added to the negatively charged nitrogen. The reaction takes place through a six-centered ring transition state [3].

Creative and profitable recycling methods for polyurethane foam have been proposed as a result of the disposal regulations. Polyurethane waste originates from various applications, including end-of-life vehicles (ELVs) and waste from electrical and electronic equipment (WEEE) [4]. The majority of polyurethane foam waste is usually incinerated or dumped in landfills but recycling the most effective and economical alternative disposal method. Polyurethane recycling routes be divided into mechanical, chemical and energy recovery. In mechanical recycling, polyurethane waste is ground into powders to be reprocessed in different ways without chemical treatment. The mechanical recycling route is convenient and straightforward, with low cost, but the recovered product's performance is poor, limiting its applications [5]. Energy recovery refers to the incineration of polyurethane foam waste' combustion to harness energy. The energy recovery method is only limited to scrap with polyurethane laminates and commingled materials. However, polyurethane foams contain flame-retardants making this method flawless. Furthermore, polyurethane foams can release toxic compounds like hydrogen cyanide, carbon monoxide and nitrogen oxides and during thermal degradation under aerobic conditions.

Chemical recycling of polyurethane follows the degradation principle due to its thermo-stable nature. The main goal of chemical recycling is to recover polyol as the main product by breaking down the urethane bonds under controlled reaction conditions. In this case, high molecular, cross-linked polyurethane is chemically broken down into lower molecular weight liquid products, which can be reintroduced into the cycle of polyurethane raw material [6]. Chemical recycling is the most sustainable recycling method due to its economic and environmental advantage compared to landfills. Chemical recycling can be achieved via hydrolysis, aminolysis and glycolysis. Glycolysis of polyurethane foam is the most environmentally friendly, widely utilized process reported in the literature with the highest development in terms of research and technological maturity. Glycolysis of polyurethane foam consists of a transesterification reaction. The hydroxyl group of the glycols replaces the ester group attached to the urethane functional groups, followed by the breaking of bonds releasing ester polyols and alcohol [7].

The Single-phase glycolysis process is currently at an industrial scale. However, the single-phase glycolysis process leads to the recovery of polyols containing active hydroxyl groups making it suitable for the production of flexible polyurethane foam [8]. The single-phase glycolysis process has been optimized through catalyst selection, post-treatment to minimize the aromatic amine content and high amount of glycols, yielding to a split-phase with high-quality rigid and flexible polyols. Diethylene glycol (DEG) and dipropylene glycol (DPG) can be used individually or mixed to enable the recovery of polyols with optimal reactivity property [9]. Utilizing both diethylene glycol (DEG) and dipropylene glycol (DPG) as the primary results in a split-phase. The upper liquid-phase is the starting polyol, and the lower liquid-phase is the diphenylmethane-diisocyanate (MDI) compounds. The upper liquid-phase is the starting polyol, and the lower liquid-phase was the diphenylmethanediisocyanate (MDI) compounds. The lower-phase is treated with propylene oxide to obtain rigid polyols. The main limitation of glycolysis is the difference in process parameters for flexible and rigid foams, which enforce segregation of used waste. This method is also significantly more effective when applied to the post-production waste due to secondary reactions resulting from high temperatures [10]. Glycolysis of polyurethane foam has been described in the literature, but the process is still on a pilot-scale due to economic and logistic reasons. The effects of recycling on mechanical and chemical properties of polyurethane foam has been widely reported in the literature.

Kraitape et al. investigated the influence of recycled polyol on the mechanical properties of flexible polyurethane foam [11]. The recycled polyol was obtained through the glycolysis process of polyurethane foam. Tensile properties and compressive properties of polyurethane foam increased with the recycled polyol functionality, including cross-link density and urea formation.

Kiss et al. studied the possible changes in the mechanical performances with the amount of recycled polyol incorporated [12]. An increase in recycled polyol content resulted in a decrease in hardness properties for the polyester-based foam owing to the fine cell structure of the glycolysate. The high content of the recycled polyol improved the tensile properties.

Trzebiatowska et al. studied the changes in the cross-link density of polyurethane synthesized with recycled polyol [13]. The urethane's cross-link density increased with the recycled polyol content, increasing glass transition temperatures and storage modulus. Tensile strength, elastic modulus, thermo-mechanical stability, and hardness of polyurethane also increased with the recycled polyol content. Recoverable deformation increased with the recycled polyol content at the expense of a decrease in elongation at break. 


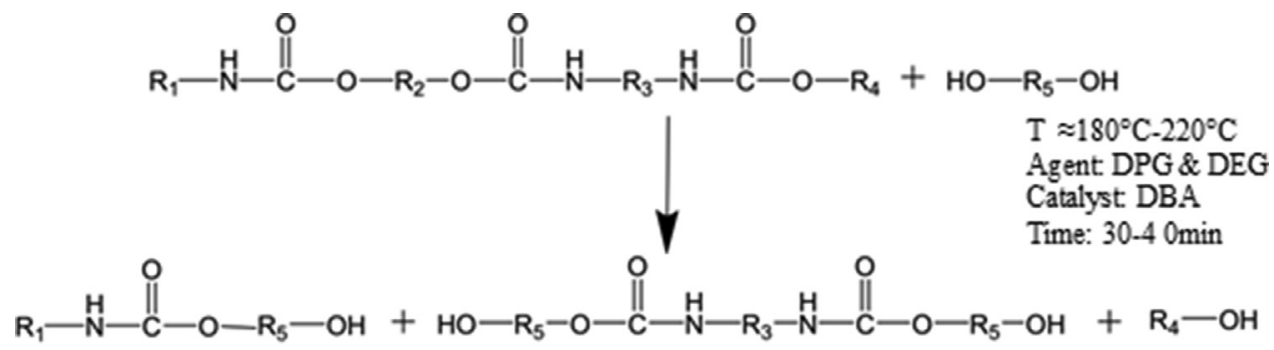

Scheme 1. Glycolysis of urethane functional group to its co-existing functional groups such as ester polyols ( $R_{1}$ and $\left.R_{3}\right)$, an alcohol ( $\left.R_{4}\right)$ and $R_{5}$ glycols.

The possibility of reversing polymerization is one unique feature of polyurethane that allows for the recovery of raw materials for polyurethane synthesis. Chemical recycling is much more demanding than mechanical considering the costs and the applied temperatures. This study aimed to determine the possible changes in thermo-mechanical properties between rigid polyurethane plastic prepared using polyols derived from depolymerization of commercial polyurethane foam with benchmark rigid polyurethane plastic. This study will allow for a better understanding of the maximum service temperature $\left(T_{\max }\right)$ at which the recycled polyurethane can be used. Determining the effects of grafting recovered polyol on the thermomechanical properties of recycled polyurethane plastic will be essential for future process optimization studies. This study will contribute to the global efforts to minimize polyurethane foam pollution and effectively contribute to the transition's effort of polyurethane material from linear to circular economy model in the plastic market industry.

\section{Experimental section}

\section{Materials}

Polyurethane foam was obtained from F.S.Fehre Automotive GmbH, WerkMarkranstädt, Germany. It was used as the primary raw material for the glycolysis process. Dipropylene glycol (DPG) and diethylene glycol (DEG) were obtained from Stockmeyer GmbH (Berlin). Di-n-butyl amine (DBA), purchased from Merck KGaA, Darmstadt, Germany, was used as a catalyst without further treatment. Lupranate M20FB, a polymeric diphenylmethane diisocyanate (p-MDI), was received from BASF Schwarzheide GmbH.

\section{Glycolysis of polyurethane foam}

In the synthesis of the recovered polyol, dipropylene glycol, diethylene glycol and di-n-butyl amine were introduced into a 1.5-liter four-necked glass flask with a nitrogen inlet, magnetic stirrer, and thermocouple with an exterior electric heating mantle, reflux condenser, and magnetic stirrer unit. A ratio of DPG: DEG of 1:1 by weight was used. The mixture (glycols/catalyst) was stirred at 500-550 rpm while gradually raising the bath temperature to $220^{\circ} \mathrm{C}$. Polyurethane foam was washed with water and then with acetone after isolating it from other materials. The foam was cut into small scrap of about 4-6 cm size using a shredder and then dried in an oven at $105^{\circ} \mathrm{C}$ for 24 h to remove water. After heating the bath to $180^{\circ} \mathrm{C}$, the first portion, one-tenth of the foam scrap's total volume, was introduced into the DEG/DPG/catalyst mixture. The rest of the foam scrap was added every ten minutes at a rate of one-tenth of the total volume as it dissolved at $180^{\circ} \mathrm{C}$. The residual mixture was stirred for another $30 \mathrm{~min}$ at $220^{\circ} \mathrm{C}$ and then cooled to ambient temperature.

Glycolysis of polyurethane foam involved high boiling-temperature glycols as decomposition reagents (see Scheme 1). The result was a split-phase mixture in which the upper liquid-phase was characterized as the starting polyol, whereas the lower liquid-phase was the derived MDI compounds. The hydroxyl numbers and amine numbers of the recovered polyol were determined according to ASTM D 4273. Viscoelastic properties were measured through the rotation and oscillation mode using a Thermo-Haake Rheostress 300, with the temperature maintained at $25^{\circ} \mathrm{C}$. Particle size and size distribution were determined using the NANOPHOX dynamic light scattering method.

\section{Synthesis of polyurethane utilizing the recovered polyol}

The recovered polyol from the glycolysis process was used as the primary raw material for the recycled polyurethane synthesis. As a primary raw material for the polyurethane production, 4, 4'-diphenylmethane diisocyanate (p-MDI) was used with an NCO content of $31 \%$. Before producing the recycled polyurethane, the recovered polyol and p-MDI were separately degassed at $100^{\circ} \mathrm{C}$ and 0.1 bar for three hours before mixing. A ratio of NCO: rec-OH of 1 : 1.5 by weight was used. The recovered polyol reacted with the p-MDI at room temperature by mixing in an aluminum beaker until the mixture was perfectly homogenous. The mixture was further degassed for another 30 seconds to remove excess gases, then poured in a closed steel mold $\left(300 \times 300 \times 5 \mathrm{~mm}^{3}\right)$ to allow curing and cross-linking for 3 hours at $80^{\circ} \mathrm{C}$ in an oven. The addition reaction between isocyanate groups (NCO) of the p-MDI and the hydroxyl groups $(-\mathrm{OH})$ of recovered polyol formed urethane linkages. The resulting polyurethane material was cured for at least $24 \mathrm{~h}$ at room temperature before further testing. 


\section{Thermal characterization}

Differential scanning calorimetry (DSC) recycled polyurethane material was performed on a DSC 204 phoenix, Netzsch, Germany, according to ISO-11357. The recycled polyurethane's glass transition temperature was determined using a periodic temperature distraction superimposed on linear heating programmed from $-100^{\circ} \mathrm{C}$ to $280^{\circ} \mathrm{C}$ using a heating rate of $10^{0} \mathrm{~K} / \mathrm{min}$ under a nitrogen atmosphere with a flow rate of $20 \mathrm{ml} / \mathrm{min}$. The measurement was performed with a $14.9 \mathrm{mg}$ of the recycled polyurethane sample cut from the core layer, sealed in a $39.7 \mathrm{mg}$ aluminium crucible. An empty aluminium crucible of $39.4 \mathrm{mg}$ was used as a reference.

\section{Mechanical Characterization}

The Ultimate tensile strength, yield strength, elastic modulus and elongation at fracture of the recycled polyurethane material were determined at three different temperatures; $24{ }^{\circ} \mathrm{C}, 40^{\circ} \mathrm{C}$, and $60^{\circ} \mathrm{C}$ on a universal tensile testing machine $(Z$ wickRoell Z020 GmbH \& Co. KG, Germany) of $20 \mathrm{kN}$ maximum load capacity equipped with a temperature chamber. The Zwick Roell temperature chamber enabled testing at different temperatures. The cross-head speed was maintained at $50 \mathrm{~mm} / \mathrm{min}$ testing at a maximum range of $1700 \mathrm{~mm}$ in a controlled temperature. Films of up to 2 mm thick were prepared according to EN ISO 527-3:1995 (ASTM D3039) using the dumbbell specimens. The samples were heated up to each specified testing temperature and maintained for 30 minutes before testing. Four measurements were averaged to determine the test parameters at each of the three temperatures. Standard deviation was computed as a quantitive measure of precision.

Average readings of Shore D hardness were obtained using a PCE-DX-DS (D) model micro-hardness tester according to ASTM D 78508 (2015) standards for plastics at $24^{\circ} \mathrm{C} 40^{\circ} \mathrm{C}$ and $60^{\circ} \mathrm{C}$. The samples were heated up to each specified testing temperature and maintained for 30 minutes before testing inside a thermostatic chamber to ensure maximum testing temperature control. The durometer was pressed down without shock until the presser foot made full contact with the sample's surface. The actual hardness reading from the drag pointer was recorded 1s after the indenter application. Eight measurements, taken at different surface points, $9 \mathrm{~mm}$ apart from each other, were averaged to determine the test parameters at each of the three temperatures. Standard deviation was computed as a quantitive measure of precision.

Impact test was conducted using an impact tester (Zwick PSW $4 \mathrm{~J}$, Germany) with a $5.5 \mathrm{~J}$ pendulum hammer to determine the resilience and a fracture type behavior at high deformation speed according to ISO 179-1 standard. For each testing temperatures; $24^{\circ} \mathrm{C}, 40^{\circ} \mathrm{C}$ and $60^{\circ} \mathrm{C}$, eight bar-shaped unnotched samples with dimensions of $100 \times 10 \times 4 \mathrm{~mm}$ were tested using edgewise configurations. A standard deviation of $5 \%$ drop weight was subtracted in each test due to air resistance to determine the actual absorbed energy. The eight measurements were averaged to determine the test parameters at each of the three temperatures. Standard deviation was computed as a quantitive measure of precision.

\section{Results and Discussions}

\section{Thermal analysis}

Thermal degradation of polyurethane is a multi-stage process that depends on its physical and chemical properties. The thermal stability of polyurethane depends on the cross-link density and the structure of the network. Thermal transitions of the recycled polyurethane and benchmark rigid polyurethane were analyzed using DSC to determine glass transition temperature $\left(\mathrm{T}_{\mathrm{g}}\right)$.

Fig. 1 shows DSC curves indicating glass transition temperatures of both recycled and benchmark rigid polyurethane on heating. The benchmark rigid polyurethane and recycled polyurethane exhibited a $\mathrm{T}_{\mathrm{g}}$ of $50.4^{\circ} \mathrm{C}$ and $43^{\circ} \mathrm{C}$, respectively. The low NCO content may have resulted in a low $\mathrm{T}_{\mathrm{g}}$ value of the recycled polyurethane compared to benchmark rigid polyurethane. Additionally, low molecular weight urethane oligomers, attributed to the breakage of molecular coherence by chain scission, may have resulted in a low $T_{g}$ value of the recycled polyurethane. Moreover, the low $T_{g}$ value of recycled polyurethane may be attributed to the breakdown of the cross-links during reactive compounding, which enhanced molecules' mobility. Generally, polyurethane appears to segregate into hard and soft domains due to thermodynamic incompatibility between the two domains [15]. Hard segments are most frequently made of nonpolar hydrocarbon structures, urethane oligomers, low-molecular-weight hydroxyl chain extenders, and urea oligomers produced using diisocyanate and amino chain extenders [16]. Two separate phase transition points are observed as two different glassy temperatures for soft segments $\left(\mathrm{T}_{\mathrm{g} 1}\right)$ and hard segments $\left(\mathrm{T}_{\mathrm{g} 2}\right)$ [17]. The larger the amorphous portion, the lower the glass transition temperature, and the narrower is this temperature range. High glycolysate content may have led to the low glass transition temperature of recycled polyurethane due to the higher mobility of polymer chains resulting from lower cross-link density. A maximum exothermic peak observed at $50^{\circ} \mathrm{C}$ for the recycled polyurethane indicated that a post-reaction occurred during the run due to trimerization reaction of highly reactive isocyanate groups with urea formation by a cleavage reaction of weak urethane groups. Properties of polyurethane such as hardness, elastic modulus, and toughness depend on the glass transition temperatures. 


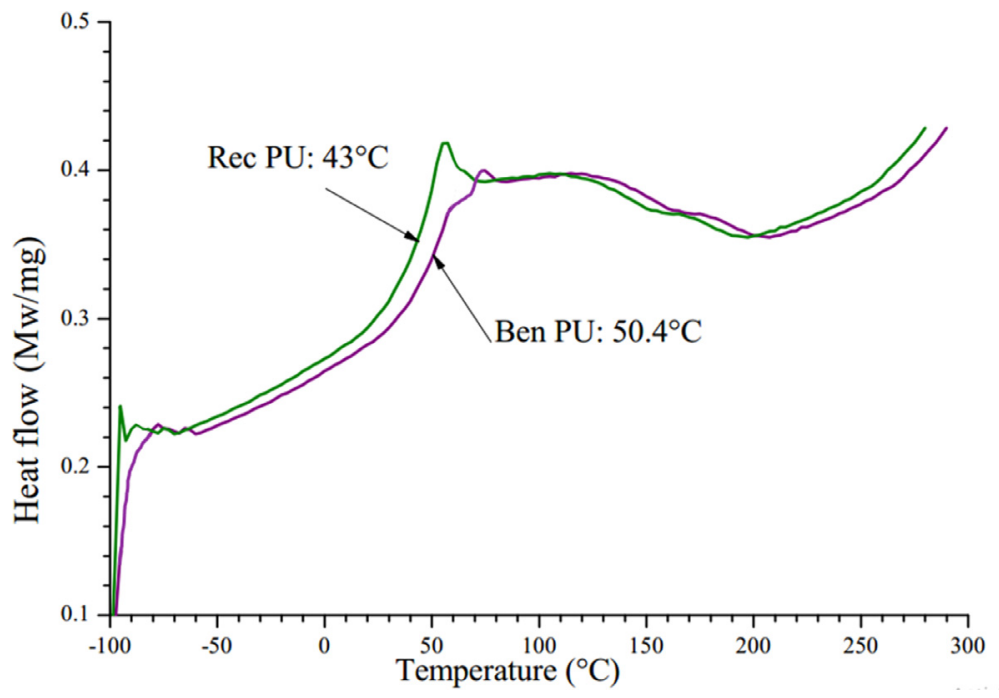

Figure 1. DSC curves for recycled and petroleum-based polyurethane. Data for the petroleum-based polyurethane was obtained from Yang et al. [14]
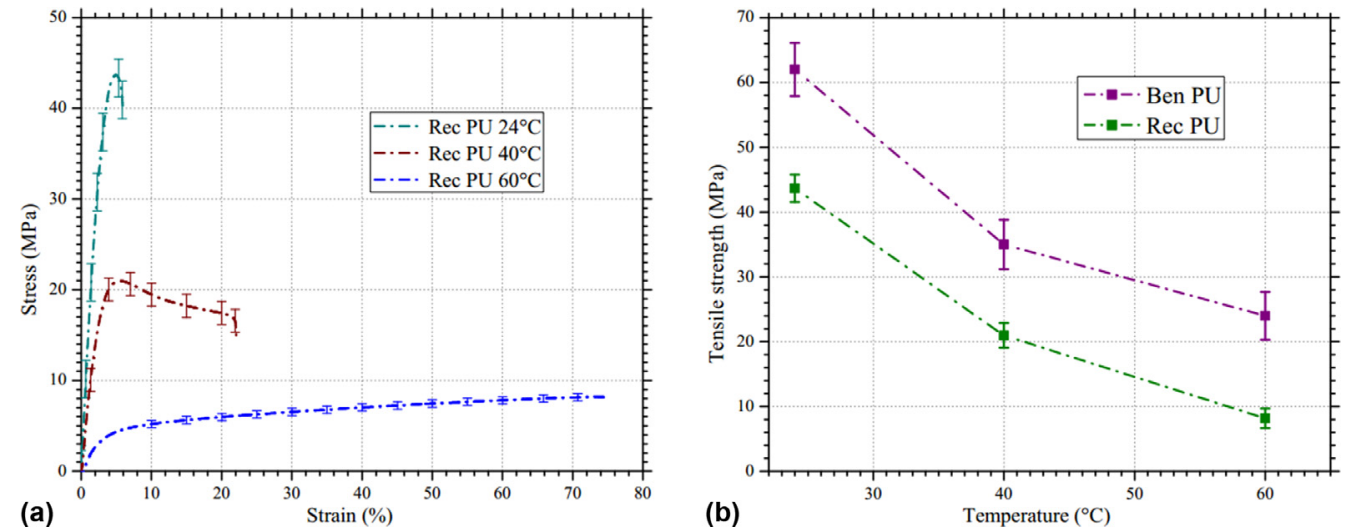

Figure 2. (a) Stress-strain behavior for recycled polyurethane at $24^{\circ} \mathrm{C}, 40^{\circ} \mathrm{C}$ and $60^{\circ} \mathrm{C}$ and (b) Tensile strength for recycled and benchmark rigid polyurethane at $24^{\circ} \mathrm{C}, 40^{\circ} \mathrm{C}$ and $60^{\circ} \mathrm{C}$. Data for benchmark rigid polyurethane was obtained from BASF Elastollan C 64 D, TP [18].

Tensile strength

A polymer's ability to resist deformation under different tensile loading and varying conditions is vital for structural mechanics applications. The ultimate tensile strength, yield strength, elastic modulus and elongation at fracture were obtained at three different temperatures; $24^{\circ} \mathrm{C}, 40^{\circ} \mathrm{C}$, and $60^{\circ} \mathrm{C}$ from the universal tensile testing machine.

Fig. 2a shows stress-strain curves of recycled polyurethane at different loading conditions. Temperature and strain rate greatly influences the mechanical properties of the polymer. Fig. $2 \mathrm{~b}$ represents the tensile strength of the recycled and benchmark rigid polyurethane as a function of temperature. At $24^{\circ} \mathrm{C}$, below the glass transition temperature $\left(\mathrm{T}_{\mathrm{g}}\right)$ of recycled polyurethane, brittle failure was observed as a break at a low strain rate at the maximum stress. High yield strength with strain hardening behavior was observed at $24^{\circ} \mathrm{C}$. At $40^{\circ} \mathrm{C}$, a characteristic yield point was observed, followed by a drop in tensile strength and breakpoint at lower stress but high strain. From the results, a loss in the yield strength by $52 \%$ was observed between $24^{\circ} \mathrm{C}$ to $40^{\circ} \mathrm{C}$ with an increase in ultimate elongation at break of $273 \%$. The decrease in yield strength is due to the rise in molecular mobility at high temperatures despite remaining entangled in the structure. The ultimate elongation at $60^{\circ} \mathrm{C}$ was greater than at $24^{\circ} \mathrm{C}$ by $1156 \%$ at low loads, while yield strength decreased by $83 \%$. Fig. $2 \mathrm{~b}$ shows that recycled polyurethane exhibited low tensile strength than benchmark rigid polyurethane by $29-43 \%$. Low tensile strength may have resulted from the reaction between the ester group of glycolysate and the amine, which led to a glycolysate with extended by the urea bond and ethylene glycol. Generally, an increase in the recycled polyol content enhances tensile properties due to high cross-linking and high urea formation [19]. The short-chain compounds may have been responsible for the accelerated gelation during the synthesis of recycled polyurethane, which resulted in limited cross-linking in the recycled polyurethane. The recycled polyurethane exhibits a higher number of short-chain polyols, which form the soft segments resulting in a polymer with greater flexibility and low tensile properties than benchmark rigid polyurethane. Low tensile 


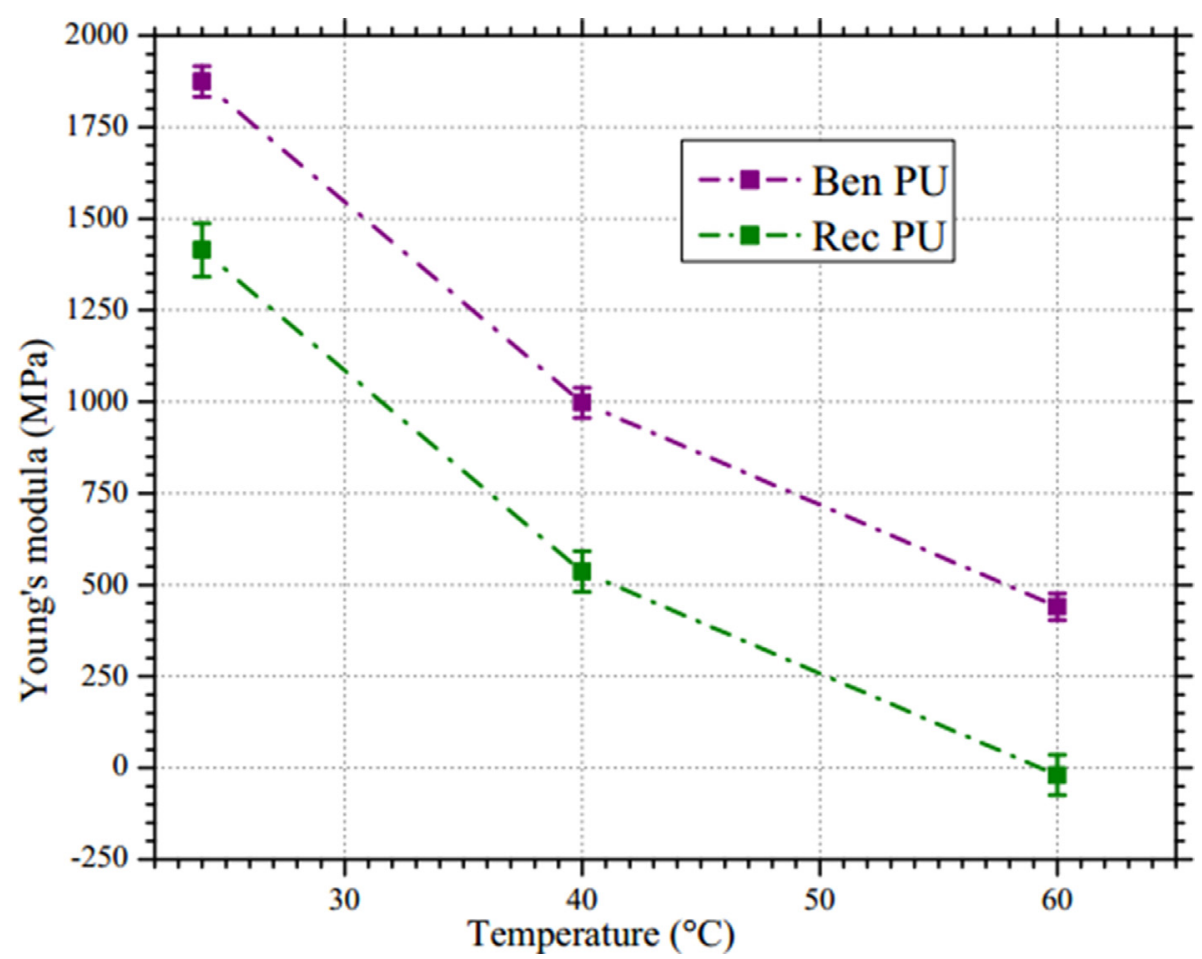

Figure 3. The elastic modulus for recycled and benchmark rigid polyurethane at $24{ }^{\circ} \mathrm{C}, 40^{\circ} \mathrm{C}$ and $60^{\circ} \mathrm{C}$. Data for benchmark rigid polyurethane was obtained from BASF Elastollan R 6000C, TP [18].

properties of recycled polyurethane may have been attributed to incorporating the low molecular weight polyester alcohols into the oligourea as a plasticizer, which improved stretchability, making it more pliable. The high amount of plasticizer can negatively affect the structure's cross-link density in the hydrated urethane, thereby decreasing its stiffness properties during accelerated thermal aging [20].

\section{Modulus of elasticity}

Elastic modulus was obtained by plotting the initial slope of the stress-strain curve using the linear regression method. Elastic modulus varies with temperature since temperature distorts the equilibrium bond distance and alters the interatomic potential angle [21].

Fig. 3 shows the results obtained from elastic modulus for the recycled and benchmark rigid polyurethane as a test temperature function. It can be observed that in the present temperature range, elastic modulus decreases linearly with increasing temperature, much similar to what was found with tensile strength. At $24^{\circ} \mathrm{C}$, short-range motions of side chains on the recycled polyurethane backbone involving short segments of chains took place due to tightly constrained molecules. A transition zone at $40^{\circ} \mathrm{C}$, slightly below $\mathrm{T}_{\mathrm{g}}$, was observed where the recycled polyurethane chains' substantial segments gained enough energy to surmount local barriers that hindered molecular motion. An increase in free volume within the rubbery plateau of the structure led to a localized side-chain movement. Generally, whole-scale translational motions of polymer chains are constrained since long polymer molecules are usually entangled at $24^{\circ} \mathrm{C}$ [22]. Chain entanglements were no longer effective in restricting molecules' thermal motion at $60^{\circ} \mathrm{C}$, above $\mathrm{T}_{\mathrm{g}}$, due to intermolecular diffusion and squeeze flow, making the material rubbery. There was a significant decrease of $52 \%$ and $62 \%$ in yield strength and modulus between $24^{\circ} \mathrm{C}$ and $40^{\circ} \mathrm{C}$, respectively. Recycled polyurethane became soft at $\mathrm{T}_{\mathrm{g}}$ due to the increase in atomic thermal vibrations, which caused the changes in lattice potential energy. Most amorphous polymers are sensitive to stress failures at elevated temperatures due to hydrocarbons in the random molecular structure. Above the $T_{g}$, the molecules possessed sufficient thermal mobility to move entirely past one another [23]. Recycled polyurethane recorded low elastic modulus than benchmark rigid polyurethane by 24-49\%. Thermo-oxidative degradation may have led to the microstructure modification during curing time. High curing and cross-linking temperatures may have initiated some chain scission. Another indicator of low modulus for the recycled polymer may have been attributed to incorporating the hydroxyl-terminated polyester alcohols into the thermally-weak allophanate bond. 


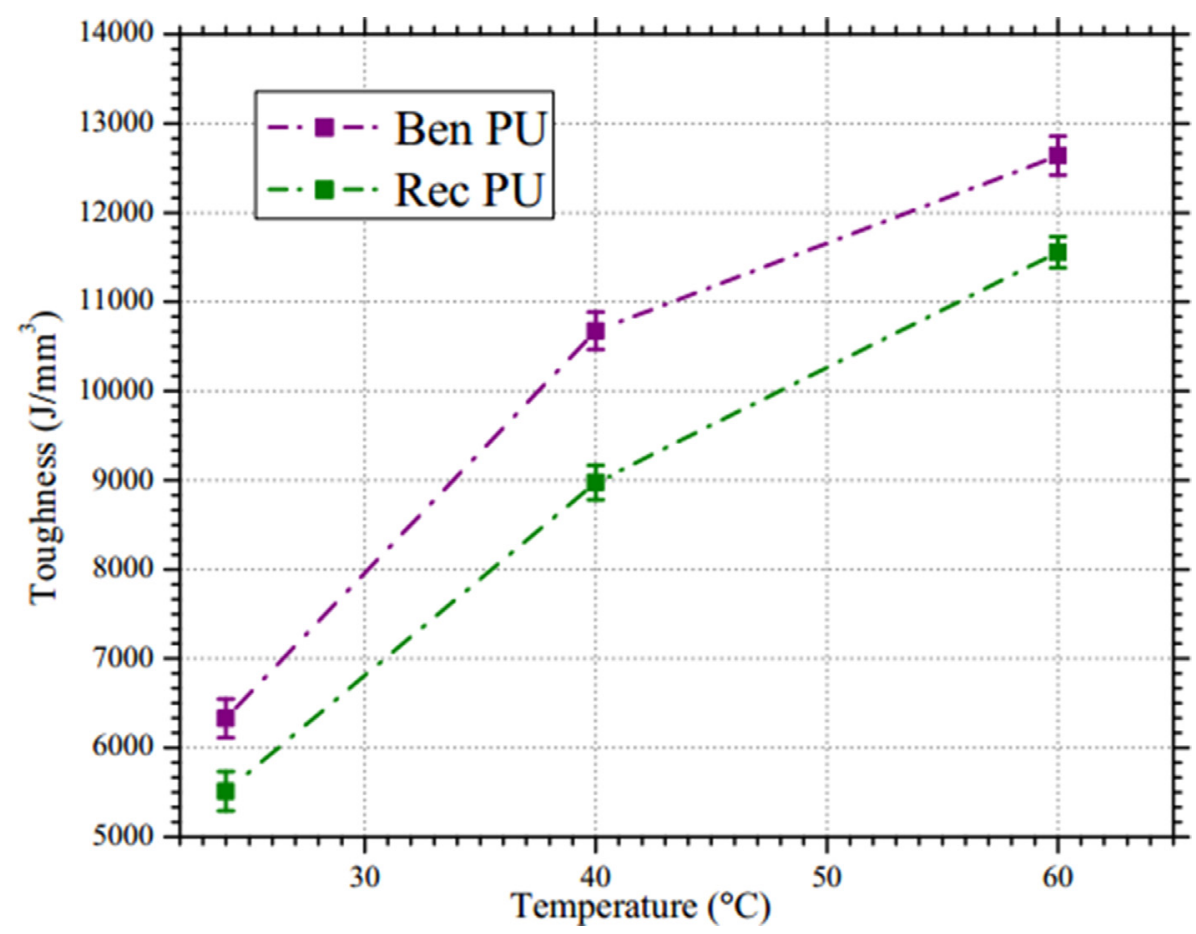

Figure 4. The relationship between toughness and temperature for recycled and benchmark rigid polyurethane at $24^{\circ} \mathrm{C}$, $40^{\circ} \mathrm{C}$, and $60^{\circ} \mathrm{C}$. Data for benchmark rigid polyurethane was obtained from Gaaz et al. [25].

\section{Toughness}

Toughness is the polymer's ability to exhibit plastic deformation and resistance to an impact load without failure. Repeated applications of stress well below the tensile strength of polymers may result in fatigue failure. Generally, toughness requires strength and ductility, which allows a material to deform before fracturing [24].

Fig. 4 shows The relationship between toughness and temperature for recycled and benchmark rigid polyurethane at different temperatures. From the results, brittle to ductile transition $\left(\mathrm{T}_{\beta}\right)$ between $24^{\circ} \mathrm{C}$ and $60^{\circ} \mathrm{C}$ was observed. Brittle samples at $24^{\circ} \mathrm{C}$ from recycled polyurethane had shiny fracture surfaces, while fibrous surfaces were observed from ductile samples at $40^{\circ} \mathrm{C}$ and $60^{\circ} \mathrm{C}$. Temperature is an intrinsic thermodynamic property that determines whether a polymer material is ductile or brittle at a given thermodynamic state [26]. High brittleness was observed at $24^{\circ} \mathrm{C}$ for the recycled polyurethane owing to the increased constraint of the molecular vibration due to low kinetic energy. An increase of 62-64\% in the absorbed energy from $24^{\circ} \mathrm{C}$ to $40^{\circ} \mathrm{C}$ was observed. This was due to the loosening of bonds between the recycled polyurethane molecules, and the sliding motion enabled to absorb energy. High toughness at $40^{\circ} \mathrm{C}$ and $60^{\circ} \mathrm{C}$ is attributed to enhanced molecular vibration, which improves its flexibility. At $60^{\circ} \mathrm{C}$, the recycled polyurethane became soft due to cross-link disruption and breakage of some hydrogen bonds. Recycled polyurethane exhibit low toughness value than benchmark rigid polyurethane by 13-15\%. Low toughness properties for the recycled polyurethane may have resulted from a high degree of crystallinity due to low molecular weight in the oligourea group.

\section{Hardness test}

Polyurethane consists of the soft segment (SS) and the hard segment (HS). The hard segment appears as dispersed in a soft segment matrix, and each segment has specific properties and applications. The hardness of polyurethane usually depends on the nature of the structure and the degree of phase separation between the soft segment (SS) and the hard segment (HS) [27].

Fig. 5 shows the results of shore D hardness for the recycled and benchmark rigid polyurethane as a function of temperatures. From the results, a decrease in hardness was observed for both polymers between $24^{\circ} \mathrm{C}$ and $60^{\circ} \mathrm{C}$. As the temperature approaches glass transition temperature $\left(\mathrm{T}_{\mathrm{g}}\right)$, both polymers become soft due to hydrogen bonds' breakage and cross-linking disruption in the polymer structure. At low temperatures, polymers' molecular attraction is much high to form a more stable structure that can resist thermal vibrations retaining its hardness [28]. At $24^{\circ} \mathrm{C}$, both polymers showed high hardness value due to constrained molecular vibration of the constituent molecules brought by low kinetic energy. Recycled polyurethane had a higher hardness than benchmark rigid polyurethane by $9-29 \%$. High shore D values of the recycled polyurethane indicated the dominating effect of the oligourea domains in the polymer structure, which led to a tough but elastic material 


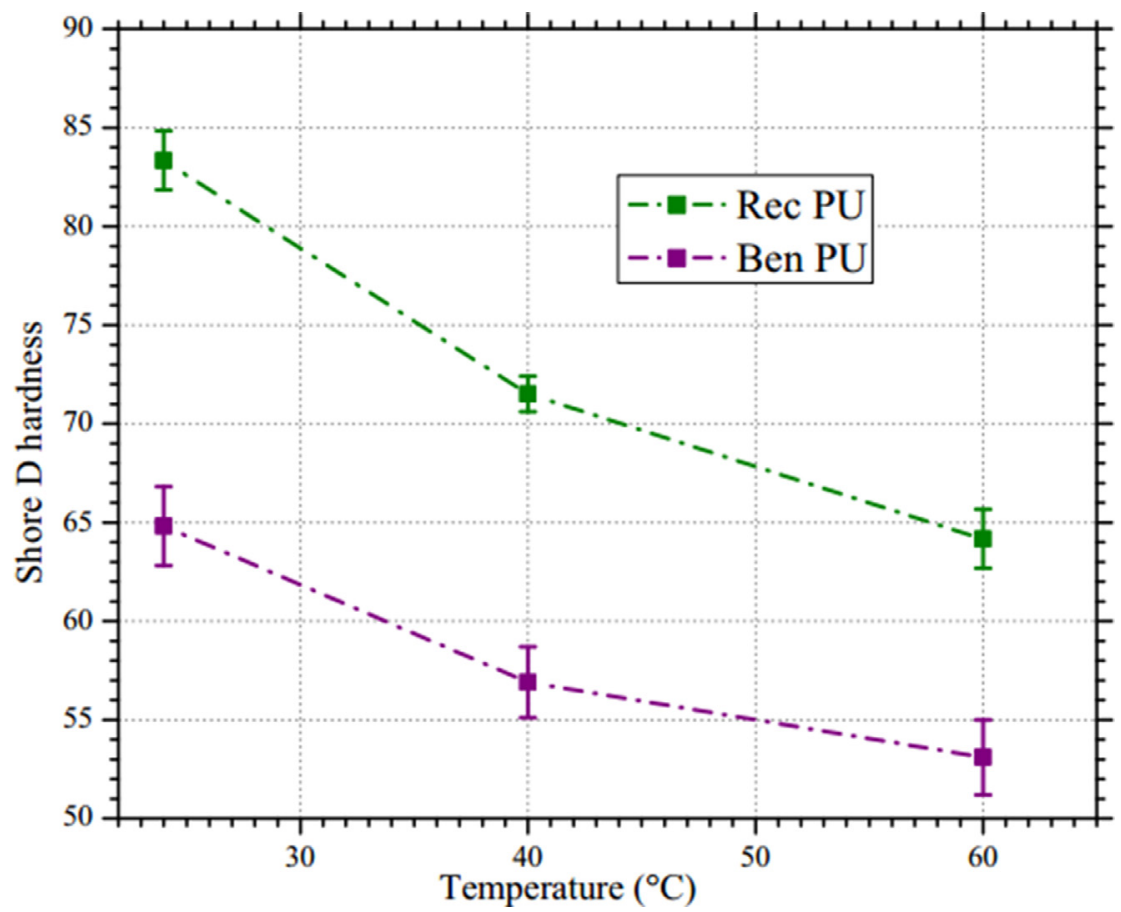

Figure 5. Hardness vs. temperature obtained for recycled polyurethane and pet benchmark rigid polyurethane at $24^{\circ} \mathrm{C}, 40^{\circ} \mathrm{C}$, and $60^{\circ} \mathrm{C}$. Data for benchmark rigid polyurethane was obtained BASF Elastollan S grade [18].

Table 1

Properties of the recovered polyol and the polymeric diphenylmethane diisocyanate used in this study.

\begin{tabular}{|c|c|c|c|c|c|c|}
\hline \multirow[t]{2}{*}{ Chemicals } & \multirow[t]{2}{*}{ Function } & \multirow[t]{2}{*}{$\mathrm{OH}$ number $(\mathrm{mgKOH} / \mathrm{g})$} & \multirow[t]{2}{*}{ Dynamic viscosity $(\mathrm{mPa} / \mathrm{s})$} & \multirow[t]{2}{*}{ Density $(\mathrm{g} / \mathrm{cm} 3)$} & \multicolumn{2}{|c|}{ Specific heat $(\mathrm{kJ} /(\mathrm{kg} . \mathrm{K})$} \\
\hline & & & & & at $20^{\circ} \mathrm{C}$ & at $80^{\circ} \mathrm{C}$ \\
\hline Recovered polyol & $(-\mathrm{OH})$ & 270 & 4.4 & - & - & - \\
\hline Lupranat M20FB & $(\mathrm{NCO})$ & - & 210 & 1.23 & 1.4 & 1.6 \\
\hline
\end{tabular}

Table 2

Thermo-mechanical properties obtained from the recycled and benchmark rigid polyurethane.

\begin{tabular}{|c|c|c|c|c|c|}
\hline \multirow{2}{*}{$\begin{array}{l}\text { T6 } \\
\text { Parameters }\end{array}$} & \multirow[b]{2}{*}{ Material } & \multicolumn{3}{|c|}{ Temperature $\left({ }^{\circ} \mathrm{C}\right)$} & \multirow[b]{2}{*}{ Ref } \\
\hline & & $24 \pm 1$ & $40 \pm 1$ & $60 \pm 1$ & \\
\hline \multirow[t]{2}{*}{ Elastic modulus (MPa) } & Rec PU & $1414.33 \pm 73$ & $536.635 \pm 55$ & (19) \pm 55 & \\
\hline & Ben PU & $1874.5 \pm 1.9$ & $997.3 \pm 40.6$ & $440.1 \pm 36.8$ & [18] \\
\hline \multirow[t]{2}{*}{ Maximum tensile strength (MPa) } & Rec PU & $43.669 \pm 2.074$ & $20.973 \pm 1.271$ & $8.19205 \pm 0.125$ & \\
\hline & Ben PU & $61.7 \pm 4.2$ & $35.4 \pm 3.8$ & $24.2 \pm 3.7$ & [18] \\
\hline \multirow[t]{2}{*}{ Toughness (J/mm2) } & Rec PU & $5512.30769 \pm 200.5$ & $8975 \pm 190.7$ & $11555.1 \pm 175$ & \\
\hline & Ben PU & $6330.1 \pm 198.3$ & $10675 \pm 209.6$ & $12640 \pm 219.6$ & [25] \\
\hline \multirow[t]{2}{*}{ Shore D hardness } & Rec PU & $83 \pm 0.9$ & $73 \pm 0.9$ & $66 \pm 0.9$ & \\
\hline & Ben PU & $64 \pm 2$ & $56 \pm 2$ & $55 \pm 2$ & [18] \\
\hline \multirow[t]{2}{*}{ Glass transition temperature } & Rec PU & $43^{\circ} \mathrm{C}$ & & & \\
\hline & Ben PU & $50.4 \pm 1^{\circ} \mathrm{C}$ & & & [14] \\
\hline
\end{tabular}

at higher temperatures. The results also reveal the presence of urethane groups serving as anti-degradant in the glycolysate structure. During accelerated thermal aging, urethane oligomers incorporated in the chain structure of the glycolysate can serve as antidegradant [20].

Table 1 shows the recovered polyol properties from the glycolysis process and the p-MDI used in this study. Table 2 shows the summary results obtained from thermo-mechanical characterization for recycled and the benchmark polyurethane. 


\section{Conclusion}

Polyurethane foam containing dispersion polyol was reacted with dipropylene glycol and diethylene glycol in the presence of a di-n-butyl amine. The recovered polyol was used as a raw material replacing $100 \%$ commercial petroleum-based polyester polyol to produce recycled rigid polyurethane. Thermal analysis was conducted to measure glass transition temperature. Tensile strength, elastic modulus, toughness, and hardness test of the recycled polyurethane were conducted under three different temperatures; $24^{\circ} \mathrm{C}, 40^{\circ} \mathrm{C}$, and $60^{\circ} \mathrm{C}$. The glass transition temperature for the recycled and benchmark rigid polyurethane occurred at $43^{\circ} \mathrm{C}$ and $50.4^{\circ} \mathrm{C}$, respectively. Tensile strength for recycled polyurethane recorded a lower value than benchmark rigid polyurethane by $29-43 \%$ and a corresponding $24-50 \%$ decrease in elastic modulus. Recycled polyurethane recorded lower toughness than benchmark rigid polyurethane by $13-16 \%$. However, the recycled polymer recorded high shored D values than benchmark rigid polyurethane by $9-29 \%$. The obtained recovered polyol indicated quite similar structure and thermal properties as the original polyol used in the polyurethane system. The present study concentrated on determining the thermo-mechanical properties of recycled polyurethane and comparing those properties with benchmark rigid polyurethane. As the current research demonstrates, further studies for process optimization would help advance the recycling of polyurethane foam. Such studies may include; (1) determining the effects of varying DEG: DPG ratio on properties of recovered polyol, (2) investigating the possibility of recovering stable polyol at various distillation temperatures, (3) studying the effect of recycled polyol $(-\mathrm{OH})$ content as a partial replacement $(30 \%, 40 \%, 50 \%, 60 \%$ and $70 \%)$ with a commercial petroleum-based polyester polyol, (4) study the effects of varying NCO:rec-OH ratio on thermo-mechanical and physical properties of recycled polyurethane and (5) develop a degradable recycled-polyurethane with suitable mechanical properties. This will contribute to the global efforts to minimize plastic pollution and effectively contribute to circular economies' efforts for polyurethane material.

\section{Declaration of Competing Interest}

The authors declare no potential conflicts of interest concerning the research, authorship, and publication of this article.

\section{Funding}

This research was funded by the Technical University of Applied Science Wildau (Germany). The funder had no role in the design, data collection and analysis, or the decision to publish the manuscript.

\section{Acknowledgments}

This research was supported by DAAD the German Academic Exchange Service under a BridGIT Project between Dedan Kimathi University of Technology and TH Wildau.

\section{References}

[1] D. Simón, et al., Sustainable polyurethanes: Chemical recycling to get it, in Environment, Energy and Climate Change I, Springer, 2014, pp. 229-260.

[2] H.W. Engels, et al., Polyurethanes: versatile materials and sustainable problem solvers for today's challenges, Angewandte Chemie International Edition 52 (36) (2013) 9422-9441.

[3] M.F. Sonnenschein, Polyurethanes: science, technology, markets, and trends, John Wiley \& Sons, 2021.

[4] P. Hennebert, Concentrations of brominated flame retardants in plastics of electrical and electronic equipment, vehicles, construction, textiles and non-food packaging: a review of occurrence and management, Detritus (12) (2020) 34.

[5] A. Kemona, M. Piotrowska, Polyurethane Recycling and Disposal: Methods and Prospects, Polymers, 12 (8) (2020) 1752.

[6] W. Yang, et al., Recycling and disposal methods for polyurethane foam wastes, Procedia Environmental Sciences 16 (2012) 167-175.

[7] D. Simón, et al., Recycling of polyurethanes from laboratory to industry, a journey towards the sustainability, Waste Management 76 (2018) $147-171$.

[8] D. Simón, et al., Novel polyol initiator from polyurethane recycling residue, Journal of Material Cycles and Waste Management 16 (3) (2014) 525-532.

[9] D. Simón, et al., Glycolysis of flexible polyurethane wastes containing polymeric polyols, Polymer degradation and stability 109 (2014) 115-121.

[10] M. Grigore, Methods of recycling, properties and applications of recycled thermoplastic polymers, Recycling 2 (4) (2017) 24.

[11] N. Kraitape, C. Thongpin, Influence of recycled polyurethane polyol on the properties of flexible polyurethane foams, Energy Procedia 89 (2016) $186-197$.

[12] G. Kiss, et al., Recovery of Flexible Polyurethane Foam Waste for Efficient Reuse in Industrial Formulations, Polymers 12 (7) (2020) 1533.

[13] P.J. Trzebiatowska, et al., The changes of crosslink density of polyurethanes synthesised with using recycled component. Chemical structure and mechanical properties investigations, Progress in Organic Coatings 115 (2018) 41-48.

[14] B. Yang, et al., Effects of moisture on the glass transition temperature of polyurethane shape memory polymer filled with nano-carbon powder, European Polymer Journal 41 (5) (2005) 1123-1128.

[15] Y. He, D. Xie, X. Zhang, The structure, microphase-separated morphology, and property of polyurethanes and polyureas, Journal of materials science 49 (21) (2014) 7339-7352.

[16] Faust, R. and X. Wei, High strength polyisobutylene polyurethanes. 2018, Google Patents.

[17] I.M. Kalogeras, Glass-transition phenomena in polymer blends, Encyclopedia of Polymer Blends 3 (2016) Structure.

[18] Elastomers, T.P., Elastollan ${ }^{\circledR}-$ Material Properties. BASF Polyurethanes GmbH. [Online]. Avaliable: http://www.polyurethanes.basf.de/pu/Elastollan [Accessed on May 2014], 2009.

[19] D. Simón, et al., Flexible polyurethane foams synthesized employing recovered polyols from glycolysis: physical and structural properties, Journal of Applied Polymer Science 134 (32) (2017) 45087.

[20] M. Włoch, U. Ostaszewska, J. Datta, The Effect of Polyurethane Glycolysate on the Structure and Properties of Natural Rubber/Carbon Black Composites, Journal of Polymers and the Environment 27 (6) (2019) 1367-1378.

[21] D. Akinwande, et al., A review on mechanics and mechanical properties of 2D materials-Graphene and beyond, Extreme Mechanics Letters 13 (2017) 42-77. 
[22] F.F. Crim, Molecular reaction dynamics across the phases: similarities and differences, Faraday discussions 157 (2012) 9-26.

[23] M. Walczak, Role and properties of the confined amorphous phase of polymers, ENSAM, Paris, 2012.

[24] J.M. Kubiak, et al., Toughening PMMA with fillers containing polymer brushes synthesized via atom transfer radical polymerization (ATRP), Polymer 117 (2017) 48-53.

[25] T.S. Gaaz, et al., Effect of starch loading on the thermo-mechanical and morphological properties of polyurethane composites, Materials, 10 (7) (2017) 777.

[26] J.E. Basconi, M.R. Shirts, Effects of temperature control algorithms on transport properties and kinetics in molecular dynamics simulations, Journal of chemical theory and computation 9 (7) (2013) 2887-2899.

[27] Peshkov, V., et al., New Polyurethanes with a polyurea matrix. 2012.

[28] A. Reghunadhan, S. Thomas, Polyurethanes: structure, properties, synthesis, characterization, and applications, in Polyurethane Polymers, Elsevier, 2017, pp. $1-16$. 